\title{
Respiration in the Cysts and Trophozoites of Giardia muris
}

\author{
By TIMOTHY A. PAGET, ${ }^{1}{ }^{*}$ EDWARD L. JARROLL, ${ }^{2}$ PAUL MANNING, ${ }^{2}$ \\ DONALD G. LINDMARK ${ }^{2}$ AND DAVID LLOYD ${ }^{1}$ \\ ${ }^{1}$ Department of Microbiology, University College, Newport Road, Cardiff CF2 1TA, UK \\ ${ }^{2}$ Department of Biology, Cleveland State University, Cleveland, Ohio 44115, USA
}

(Received 14 March 1988; revised 17 August 1988; accepted 17 October 1988)

\begin{abstract}
Cysts and trophozoites of the parasitic protozoon Giardia muris both showed respiratory activity but respiration in cysts was only 10 to $20 \%$ that of trophozoites. The $\mathrm{O}_{2}$ dependence of respiration in cysts and trophozoites showed $\mathrm{O}_{2}$ maxima above which respiration decreased. The $\mathrm{O}_{2}$ concentration at which the respiration rate was greatest was higher for cysts than trophozoites. The effects of various inhibitors on cyst and trophozoite respiration suggested that flavoproteins and quinones play some role in respiration. The substrate specificities and the effects of inhibitors on $G$. muris trophozoites were similar to those observed for Giardia lamblia. Metronidazole, the drug most commonly used in the treatment of giardiasis completely inhibited respiration and motility in trophozoites; however, it had no effect on either respiration or viability in cysts. Menadione, a redox cycling naphthoquinone, stimulated then completely inhibited respiration in cysts and trophozoites; a complete loss of cyst viability or trophozoite motility was also observed. The effects of menadione on G. muris may indicate that redox cycling compounds have potential as chemotherapeutic agents for the treatment of giardiasis.
\end{abstract}

\section{INTRODUCTION}

Flagellated, parasitic protozoa belonging to the genus Giardia infect humans and a wide variety of other vertebrate hosts. The life cycle of this protozoon is simple and direct, and although it requires no intermediate host, it passes through two morphologically distinct forms: the trophozoite and the cyst. The trophozoite colonizes the upper small intestine, and for reasons as yet unknown, rounds up and elaborates a cyst wall. The resulting cyst is shed with the faeces. Transmission of Giardia occurs when viable cysts are ingested with food or drink (Meyer \& Jarroll, 1980). In humans, transmission is by the faecal-oral and venereal routes. Numerous waterborne outbreaks of the disease related to community water systems have been widely publicized (Craun, 1986). Giardia lamblia (syn. G. intestinalis and Lamblia intestinalis), the human pathogen, is regarded as numerically the most important cause of waterborne infectious disease in the UK and the USA (Meyer \& Jarroll, 1980).

Since cysts are responsible for transmission there have been many reports in recent years dealing with methods for killing cysts in water supplies (Jarroll, 1988). The earliest experiments were done mainly with cysts isolated from humans with giardiasis. Such cyst supplies are rare and unreliable. More recently, Giardia muris has been proposed as a model for human cysts. $G$. muris can be isolated from mice and represents a distinct species in the genus. It was chosen because it is reliably available in large quantities from laboratory mice, and because its levels of in vitro excystation are generally high $(>90 \%)$. Because $G$. muris cysts are more resistant to chlorine than those of $G$. lamblia they are also suitable for use in monitoring water treatment processes.

Abbreviation: DBMQ, dibromothymoquinone. 
Unfortunately, even less is known about the basic physiology and metabolism of $G$. muris than that of G. lamblia. In part, this is because trophozoites of $G$. muris have not been cultured in vitro. Information on the carbohydrate and energy metabolism of Giardia has been limited to that obtained from axenically cultured G. lamblia trophozoites (Lindmark, 1980; Weinbach, 1980; Jarroll et al., 1981). What is known of energy metabolism in G. muris comes from a single study by Lindmark \& Miller (1987) which was confined to a comparison of enzyme activities in cysts and trophozoites of $G$. lamblia and $G$. muris. No pronounced differences in many enzyme activities of carbohydrate and energy metabolism were detected, but the metabolic activity of cyst forms was not assessed. The first suggestion that Giardia cysts might be metabolically active came from a report by Bingham et al. (1979), which showed that $G$. lamblia cysts were only viable for about $4 \mathrm{~d}$ when maintained in water at $37^{\circ} \mathrm{C}$. At a water temperature of $8{ }^{\circ} \mathrm{C}$ cysts survived for about 2 months. This temperature-dependent survival suggested that cysts are metabolically active rather than true cryptobiotic forms.

In this paper we determine the rates of $\mathrm{O}_{2}$ uptake in cysts and trophozoites of $G$. muris and investigate the effects of temperature on the respiration of cysts. We also compare the effects of various substrates and metabolic inhibitors on $\mathrm{O}_{2}$ uptake in cysts and trophozoites.

\section{METHODS}

Growth and maintenance of the organism. G. muris was maintained by passage of cysts into 4-6-week-old female CF-W mice as described by Roberts-Thompson et al. (1976); $5 \mathrm{~d}$ post-infection, cysts were passed in faeces and continued to be passed for up to 3 weeks after infection. Cysts were collected daily and purified on sucrose and Percoll gradients to remove contaminating bacteria according to the procedure described by Sauch (1984). Purified cysts were resuspended in distilled water supplemented with an antibiotic mixture $(10 \%, \mathrm{v} / \mathrm{v})$ containing $20 \mathrm{mg}$ streptomycin sulphate $\mathrm{ml}^{-1}$ and $12 \mathrm{mg}$ benzylpenicillin $\mathrm{ml}^{-1}$. Cysts were maintained at $4{ }^{\circ} \mathrm{C}$ prior to use. The usual yield from 30 mice was $1.5 \times 10^{8}$ cysts.

Trophozoites of $G$. muris were obtained by excystation of cysts after acid induction as described by Rice \& Schaefer (1981). Enumeration of cysts and trophozoites was done using a Neubauer haemocytometer.

Measurements of $\mathrm{O}_{2}$ uptake. Measurements of respiration were made in a thermostatically controlled oxygen electrode vessel open for gases (Degn et al., 1980), comprising a $5 \mathrm{ml}$ stirred reaction vessel. Measurements of respiration were made under defined $\mathrm{O}_{2} / \mathrm{N}_{2}$ ratios as described previously (Lloyd et al., 1982, 1983). Gases used were $\mathrm{N}_{2}$ and a mixture of $4.9 \%(\mathrm{v} / \mathrm{v}) \mathrm{O}_{2}$ in $\mathrm{N}_{2}$ (Matheson, USA). Gas mixtures were obtained using a digital gas mixer (Lloyd, 1985) which produces ratios of the two gases in $5 \%$ steps. Calibration of gas mixtures was done as described by Paget et al. (1987). Buffer saturated with 4.9\% $\mathrm{O}_{2}$ contained $50 \mu \mathrm{M}-\mathrm{O}_{2}$ at $37{ }^{\circ} \mathrm{C}, 59 \mu \mathrm{M}-\mathrm{O}_{2}$ at $27^{\circ} \mathrm{C}$ and $71 \mu \mathrm{M}-\mathrm{O}_{2}$ at $17^{\circ} \mathrm{C}$ (Wilhelm et al., 1977). For the determination of respiratory activities, cysts and trophozoites were suspended in a modified Tyrodes' buffer, as described by Rice \& Schaefer (1981).

Trophozoite motility and cyst viability were determined at the end of each experiment. Trophozoite motility was determined microscopically by examination of 500 trophozoites. To calculate cyst viability, cysts were removed from the reaction vessel and excystation was induced as described previously. The number of cysts and trophozoites was counted $1 \mathrm{~h}$ after excystation. The percentage excystation was then calculated correcting for the production of two trophozoites per cyst (Rice \& Schaefer, 1981).

Chemicals. All substrates, quinacrine, chloroquine, oubain and $\mathrm{NaNO}_{2}$ were dissolved in a glucose-free Tyrode's buffer (Rice \& Schaefer, 1981). All other inhibitors were dissolved initially in DMSO, which at the concentrations used has no effects on cysts or trophozoites. All chemicals were obtained from Sigma except Dglucose and $\mathrm{NaNO}_{2}$, which were from BDH. All other chemicals and solvents used were of analytical grade.

\section{RESULTS}

\section{Effects of substrates on $\mathrm{O}_{2}$ uptake in cysts and trophozoites of $\mathrm{G}$. muris}

The effect of various substrates on endogenous respiration in the cyst and trophozoite forms of G. muris is shown in Table 1. Cysts were unable to utilize sugars and sodium succinate; however, ethanol significantly stimulated respiration. In the trophozoite all substrates with the exception of sodium succinate stimulated respiration. Endogenous respiration in both cysts and trophozoites was inhibited by acetate. 


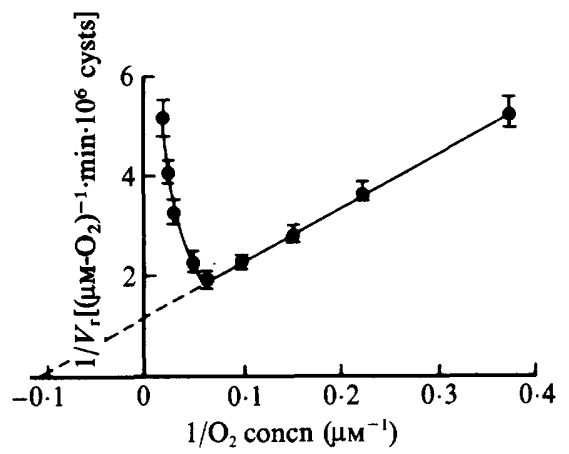

Fig. 1. Reciprocal plot of respiration rate against increasing $\mathrm{O}_{2}$ concentration $(0-50 \mu \mathrm{M})$ for $G$. muris cysts respiring endogenous substrate; $1.2 \times 10^{7}$ cysts were used for each determination and all experiments were done at $37^{\circ} \mathrm{C}$. Error bars indicate SEM values, calculated from data obtained in four experiments.

Table 1. Effects of substrates on respiration in the trophozoite and cyst forms of G. muris

The effects of substrates on respiration of cysts and trophozoites of $G$. muris were determined using an open oxygen electrode. For each determination, $1.2 \times 10^{7}$ cysts or $2 \times 10^{6}$ trophozoites were used; all experiments were done at $37^{\circ} \mathrm{C}$ with a gas phase consisting of $1.01 \mathrm{kPa} \mathrm{O}_{2}$ in $\mathrm{N}_{2}$. Inhibition or stimulation of respiration is expressed as a percentage of the endogenous respiration. Endogenous respiratory rates were $0.48 \mu \mathrm{M}-\mathrm{O}_{2} \mathrm{~min}^{-1}$ per $10^{6}$ cysts and $2.2 \mu \mathrm{M}-\mathrm{O}_{2} \mathrm{~min}^{-1}$ per $10^{6}$ trophozoites. Values expressed were typical of those determined from three experiments giving similar results. All substrates were added to a final concentration of $40 \mathrm{mM}$.

Percentage inhibition or stimulation $(-)$ of respiration

Substrate

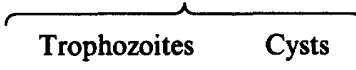

None

D-Glucose

D-Fructose

Succinate

Acetate

Ethanol

$\begin{array}{rr}0 & 0 \\ 76 & 0 \\ 5 & 0 \\ 0 & 0 \\ -29 & -24 \\ 74 & 105\end{array}$

\section{$\mathrm{O}_{2}$ dependence of respiration in cysts and trophozoites}

The $\mathrm{O}_{2}$ dependence of respiration in cysts utilizing endogenous substrate (Fig. 1) shows that respiration increases with increasing $\mathrm{O}_{2}$ concentration over the range $0-25 \mu \mathrm{M}-\mathrm{O}_{2}$, and at $\mathrm{O}_{2}$ concentrations greater than $25 \mu \mathrm{M}-\mathrm{O}_{2}$ respiration decreases. In the presence of ethanol the $\mathrm{O}_{2}$ dependence of respiration followed a similar pattern to that shown in Fig. 1: the results from double reciprocal plots are shown in Table 2 . No significant variation was observed in the sensitivities of endogenous or ethanol-supported respiration to elevated $\mathrm{O}_{2}$ concentration; however, a marked difference was observed in their apparent $\mathrm{O}_{2}$ affinities.

The dependence on $\mathrm{O}_{2}$ of D-glucose or ethanol-supported respiration in G. muris trophozoites followed a similar pattern to that observed in Fig. 1: results are shown in Table 2. For both substrates, respiration was more sensitive to $\mathrm{O}_{2}$ than that observed in cysts. Apparent $K_{\mathrm{m}}$ values for $\mathrm{O}_{2}$ indicate that trophozoites have a higher affinity for $\mathrm{O}_{2}$ than cysts.

The effect of increasing cyst number on the measured endogenous respiratory rate (Fig. 2) shows that rates of $\mathrm{O}_{2}$ uptake were proportional to cyst numbers. Interestingly, a significant decrease in the $\mathrm{O}_{2}$ concentration above which respiration was inhibited was observed as cyst numbers were increased.

The temperature dependence of respiratory activity in $G$. muris cysts is shown in Fig. 3. A decrease in temperature from $37-17^{\circ} \mathrm{C}$ produced an $82 \%$ reduction in respiratory activity; a $Q_{10}$ 


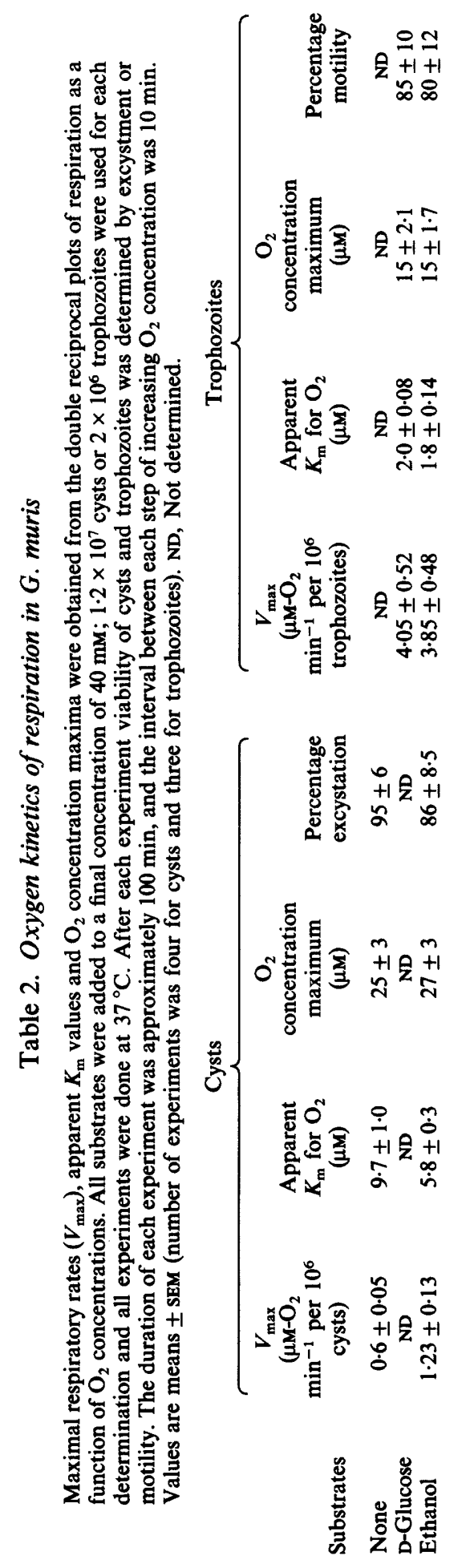




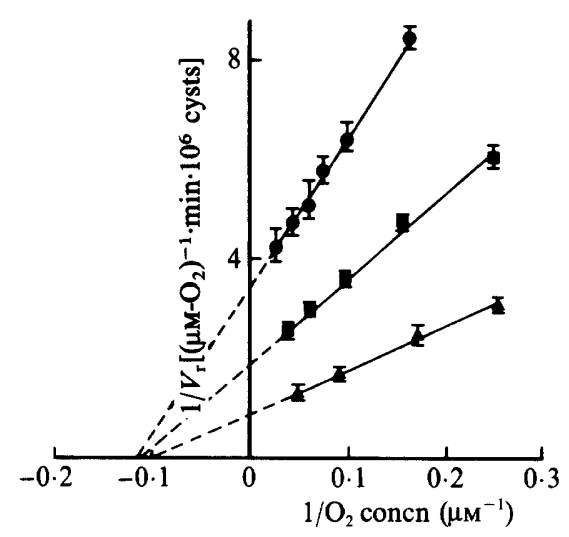

Fig. 2. Reciprocal plots of respiration rate against increasing $\mathrm{O}_{2}$ concentration for $G$. muris cysts respiring endogenous substrate: the effects of increasing cyst number is shown. Only the linear portion of the graph is shown and conditions used are those described in Fig. 1. Error bars indicate sEM values calculated from data obtained in four experiments. Number of cysts:, $4.8 \times 10^{6} ; \square, 9.6 \times 10^{6} ; \Delta$, $1.9 \times 10^{7}$.

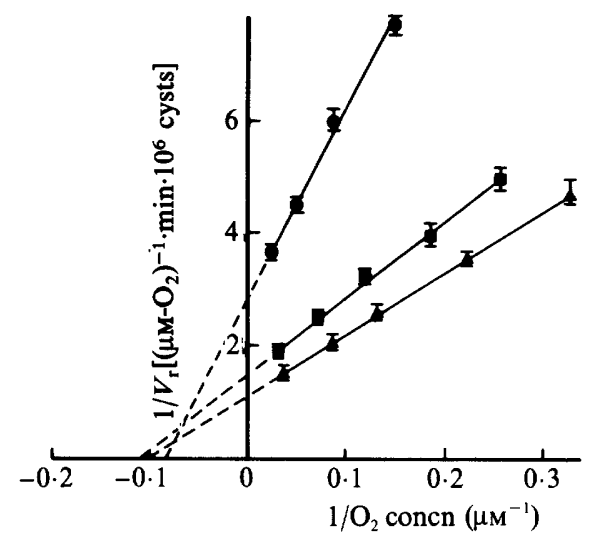

Fig. 3. Effect of temperature on the $\mathrm{O}_{2}$ dependence of respiration; $\triangle, 37^{\circ} \mathrm{C} ; \square, 27^{\circ} \mathrm{C} ; 0,17^{\circ} \mathrm{C}$. Conditions used were those described in Fig. 1. Only the linear portion of the graph is shown. Error bars indicate SEM values, calculated from data obtained in four experiments.

value of 0.85 was calculated from these data. A marked decrease in the sensitivity of respiration to $\mathrm{O}_{2}$ inhibition was observed with decreasing temperature.

Cyst viability or trophozoite motility, determined after exposure to $\mathrm{O}_{2}$ concentrations up to $50 \mu \mathrm{M}$, was never significantly different to controls maintained under $\mathrm{N}_{2}$.

\section{Effects of inhibitors on respiration in $G$. muris cysts}

The effects of various inhibitors on respiration and viability in cysts of $G$. muris is shown in Table 3. It can be seen that ethanol-supported $\mathrm{O}_{2}$ uptake was more sensitive to this range of inhibitors than endogenous respiration; however, the effect of inhibitors on cyst viability was similar. Acetate, a major product of aerobic carbohydrate metabolism, markedly inhibited respiration and cyst viability. Interestingly metronidazole, a drug used in the treatment of giardiasis, had no effect on respiration or viability. $\mathrm{NaNO}_{2}$ completely inhibited respiration and viability in cysts. Other anti-protozoal drugs such as quinacrine and chloroquine had little effect on respiration but significantly reduced cyst viability; similar effects were observed with the ATPase inhibitors quercetin and oubain, and the thiol reagent $p$-chloromercuribenzoate. The 


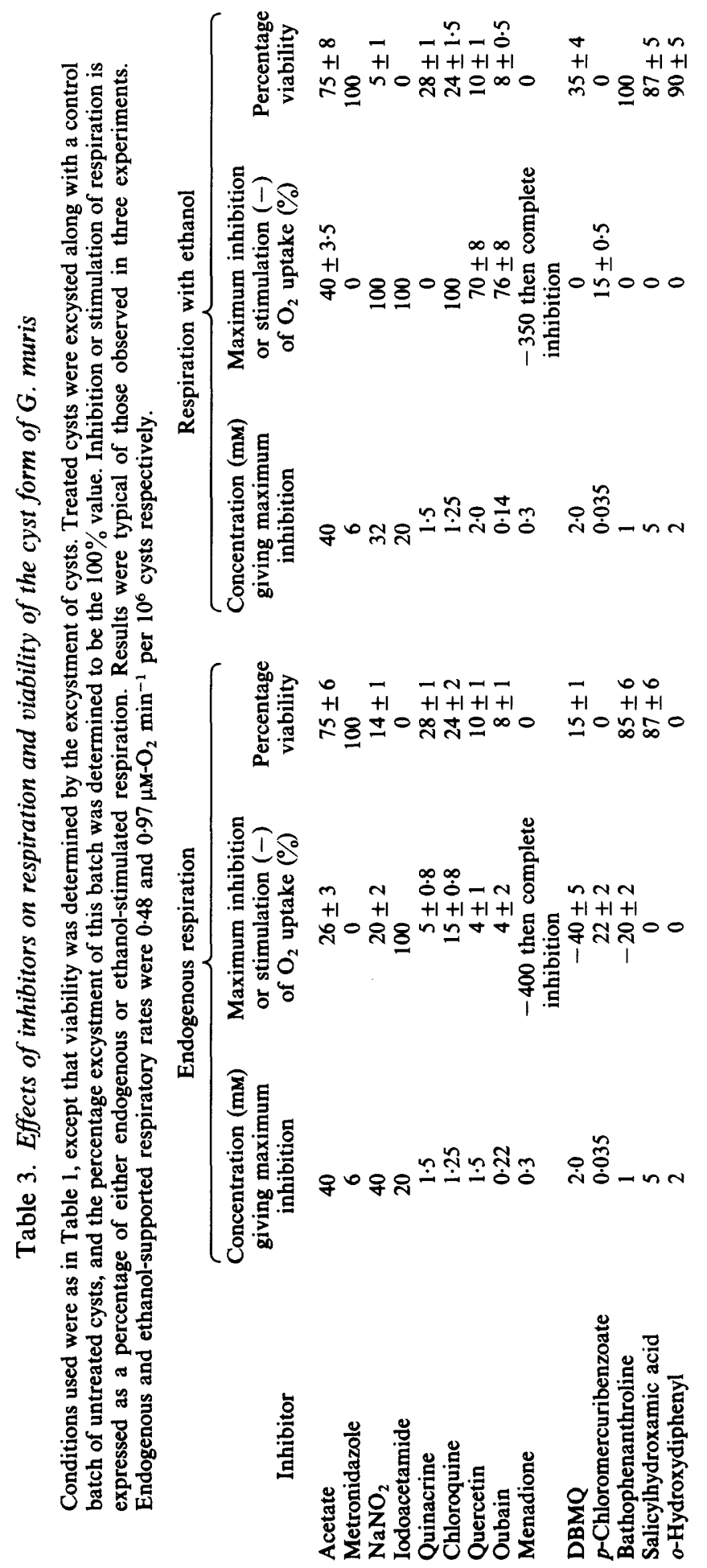


effects of menadione on endogenous respiration in cysts was complex. Over a period of $30 \mathrm{~min}$, menadione stimulated $\mathrm{O}_{2}$ uptake; this stimulation was followed by a decrease in respiratory activity, which ceased completely after $1 \mathrm{~h}$. A complete loss of cyst viability was also observed. Menadione had a similar effect on cysts respiring ethanol. DBMQ and bathophenanthroline, a transition metal chelator, also stimulated respiration and significantly reduced cyst viability. Inhibitors of alternative electron transport, salicylhydroxamic acid and $o$-hydroxydiphenyl, had no effect on either cyst respiration or viability.

\section{Effects of inhibitors on respiration in trophozoites of G. muris}

The effects of various inhibitors on respiration and motility in trophozoites of $G$. muris are shown in Table 4. The inhibitor sensitivities of respiration and motility in trophozoites utilizing endogenous substrate were similar to those observed for cysts except that metronidazole completely inhibited trophozoite motility and significantly reduced respiration. The effects of inhibitors on trophozoite respiration in the presence of D-glucose were similar to those observed for endogenous respiration; however, D-glucose-supported respiration was more sensitive to chloroquine, metronidazole and $\mathrm{NaNO}_{2}$. The effects of inhibitors on respiration in the presence of ethanol were different: metronidazole, $\mathrm{NaNO}_{2}$ and iodoacetamide completely inhibited respiration and motility; respiration was also more sensitive to chloroquine, oubain and acetate but less sensitive to quinacrine and $p$-chloromercuribenzoate.

\section{DISCUSSION}

The results reported in this paper indicate that cysts of $G$. muris have respiratory activity. This is the first report of such activity in the cyst form of any species of Giardia. The respiratory activity of $G$. muris cysts was approximately 10 to $20 \%$ that of the trophozoite; a marked variation in substrate specificity between these two forms was observed.

The inability of G. muris cysts to utilize sugars and succinate cannot be due to low activities of the enzymes of carbohydrate metabolism, as Lindmark \& Miller (1987) showed that the activities of these enzymes were no different from those of trophozoites. Thus, the inability of cysts to utilize sugars may be a consequence of the high levels of endogenous substrate (glycogen) present within the cyst $(10 \%$ of the dry wt: Kulda \& Nohynkova, 1978). The presence of endogenous substrates may prevent active sugar uptake or the transport systems may be absent. Respiration was, however, stimulated by ethanol, which can probably diffuse passively into the cysts. The substrate specificity of $G$. muris trophozoites was similar to that observed previously for G. lamblia (Lindmark, 1980) and variation in apparent $\mathrm{O}_{2}$ affinities between cysts and trophozoites would seem to reflect the differences in their respective respiratory rates.

The most striking feature of respiration in cysts and trophozoites of $G$. muris was the presence of a maximum $\mathrm{O}_{2}$ concentration above which $\mathrm{O}_{2}$ consumption decreased. The $\mathrm{O}_{2}$ concentration at which this occurred in cysts was much greater than in trophozoites, indicating that respiration in cysts is more resistant to higher $\mathrm{O}_{2}$ concentrations. This inhibition of respiration was irreversible; however, loss of respiratory activity did not affect cyst viability or trophozoite motility. A loss of trophozoite motility during long term exposure to $5 \% \mathrm{O}_{2}$ has been observed previously in G. lamblia (Gillin \& Diamond, 1981). $\mathrm{O}_{2}$ maxima have been observed in several organisms including the protozoal parasite Trichomonas vaginalis (Yarlett et al., 1987) and in the gut-dwelling nematodes Nippostrongylus brasiliensis (Paget et al., 1987a,b) and Ascaridia galli (Paget et al., 1988). In these organisms $\mathrm{O}_{2}$-mediated toxicity was correlated with the production of $\mathrm{H}_{2} \mathrm{O}_{2}$ generated by electron transport. Whether the inhibition of respiration in G. muris is linked to the production of active $\mathrm{O}_{2}$ species such as $\mathrm{H}_{2} \mathrm{O}_{2}$ and $\mathrm{O}_{2}{ }^{-}$remains to be investigated.

The effects of temperature on respiration in cysts indicated that respiration would be negligible at temperatures below $7{ }^{\circ} \mathrm{C}$; lower temperatures also favour cyst viability (Bingham et al., 1979). These two factors may be linked: at reduced temperatures the rate of endogenous substrate utilization would be decreased which may extend the lifetime of cysts. If the temperature dependency of respiration and viability in $G$. muris and G. lamblia cysts is similar then these results may explain the high incidence of giardiasis that occurs in populations where 


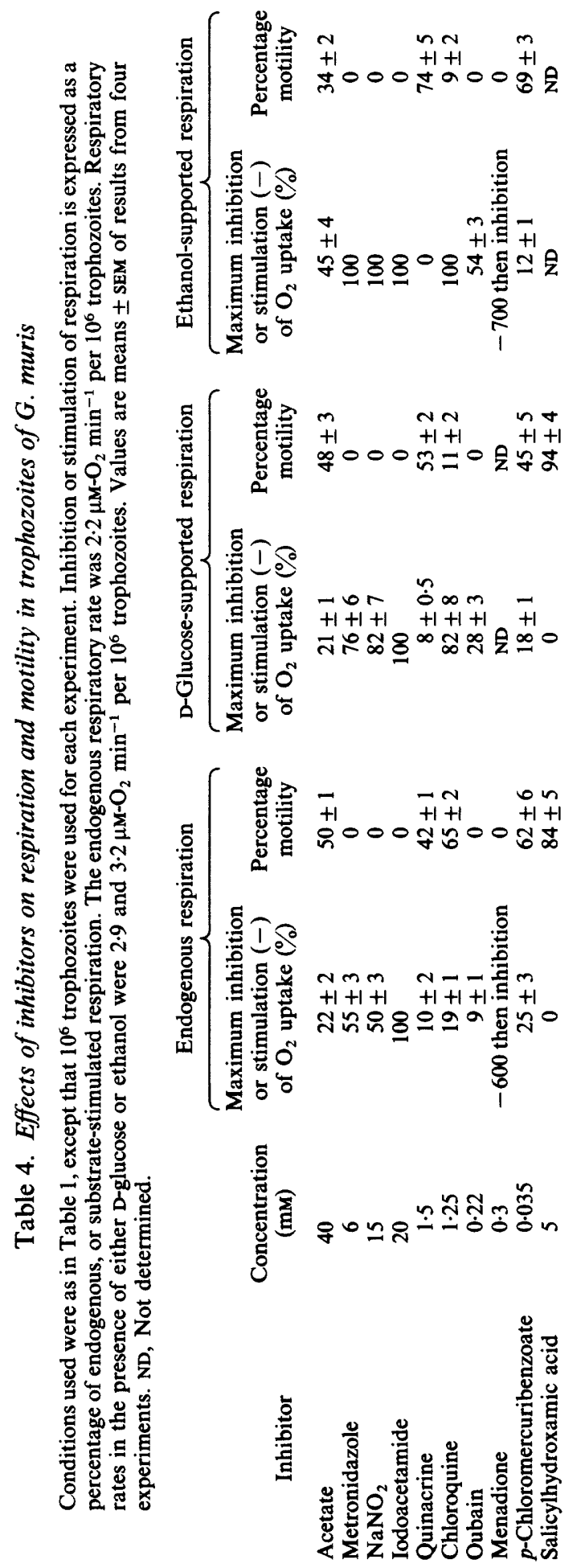


water is untreated and supplied from cold streams (Veazie et al., 1978; Wright \& Vernon, 1976; Shaw et al., 1977). In such cold waters cysts would remain viable longer, thereby increasing the chance of infection.

The effects of inhibitors on respiration in both cysts and trophozoites was similar. Cyanideinsensitive respiration has been observed in a wide range of free living and parasitic organisms (Lloyd et al., 1983; Paget et al., 1987a). In these organisms, respiration was sensitive to inhibition by $o$-hydroxydiphenyl and salicylhydroxamic acid but this was not found in G. muris. It would seem unlikely, therefore, that the respiration of $G$. muris is similar to cyanideinsensitive respiration observed in such organisms.

The effect of iodoacetamide on respiration suggests that glycolysis plays a role in respiration, possibly via the generation of $\mathrm{NAD}(\mathrm{P}) \mathrm{H}$. The effects of chloroquine and quinacrine may indicate that flavoproteins and, to a lesser extent, quinones play a role in respiration. The evidence for the involvement of iron-sulphur proteins in respiration is less clear. These conclusions are similar to those published previously by Weinbach (1980) and Lindmark (1980) and may be further evidence for a respiratory chain in G. muris similar to that described by Weinbach (1980).

Oubain and quercetin, agents that inhibit plasma membrane ATPases (Glick, 1970) both had a pronounced inhibitory effect on ethanol-supported respiration, but not endogenous respiration in cysts of $G$. muris. The inhibition of respiration in cysts and trophozoites by acetate might be explained using the pathway of acetate formation proposed by Lindmark (1980).

Interesting effects were observed with the inhibitors menadione and metronidazole. The drug metronidazole completely inhibited respiration in G. muris trophozoites but had no effect on cyst respiration or viability. When metronidazole is bioreduced by an iron-sulphur centre of the pyruvate : ferredoxin oxidoreductase in $T$. vaginalis, a nitro-radical anion is generated and this species is thought to elicit cytotoxicity within the cell (Moreno et al., 1983; Lloyd \& Pedersen, 1985; Chapman et al., 1985). $\mathrm{NaNO}_{2}$ is believed to destroy an iron-sulphur centre of the pyruvate : ferredoxin oxidoreductase in anaerobic bacteria (Clostridium sporogenes; Woods et al., 1981) and was shown to inhibit respiration and viability in G. muris cysts and trophozoites. If the sites of action of $\mathrm{NaNO}_{2}$ and metronidazole are similar it seems likely that the inability of metronidazole to inhibit respiration or to reduce viability of cysts is due to impermeability of the cysts to the drug. If the cyst form of $G$. lamblia shows the same resistance to metronidazole, then patients with giardiasis would probably pass viable cysts for several days after treatment with metronidazole.

Menadione, a redox-cycling napthoquinone (De Groot et al., 1985) has a complex mode of action. When menadione is bioreduced by an electron-donating system, it reacts with $\mathrm{O}_{2}$, thereby causing an apparent stimulation of $\mathrm{O}_{2}$ uptake. Its reaction with $\mathrm{O}_{2}$ generates active $\mathrm{O}_{2}$ species (De Groot et al., 1985) and this may be linked to the inhibition of respiration and viability. Ames et al. (1987) suggested that electron transfer and the generation of active $\mathrm{O}_{2}$ species may play a role in the action of various anti-protozoal drugs; the effects of menadione would suggest that compounds that generate $\mathrm{O}_{2}$ radicals, may have potential as chemotherapeutic agents for the treatment of giardiasis.

This work was carried out during the tenure of a Wellcome Trust Postdoctoral Fellowship by T. A.P. Dr Paget wishes to thank the Wellcome Trust for providing a travel grant. The authors acknowledge the Cleveland State University, College of Graduate Studies, for its support of this collaborative project.

\section{REFERENCES}

Ames, J. R., Hollstein, U., Gagneux, A. R., Ryan, M. D. \& Kovacic, P. (1987). An integrated concept of amoebicidal action: electron transfer and oxy radicals. Free Radical Biology and Medicine 3, 85-96.

Bingham, A. K., Jarroll, E. L., Meyer, E. A. \& RADUlEsCU, S. (1979). Giardia sp.: physical factors of excystation in vitro and vs. excystation eosin exclusion as determinants of viability. Experimental Parasitology 47, 284-291.

Chapman, A., Cammack, R., Linstead, D. \& Lloyd, D. (1985). The generation of metronidazole radicals in hydrogenosomes isolated from Trichomonas vaginalis. Journal of General Microbiology 131, 21412144. 
Craun, G. (1986). Waterborne giardiasis in the United States 1965-84. Lancet 2, 513-517.

Degn, H., Lundsgaard, J. S., Petersen, L. C. \& ORMICKI, A. (1980). Polarographic measurements of steady state kinetics of oxygen uptake by biochemical samples. Methods of Biochemical Analysis 26, 4777.

De Groot, H., Nöll, T. \& Beis, H. (1985). Oxygen dependence and subcellular partitioning of hepatic menadione-mediated oxygen uptake. Archives of Biochemistry and Biophysics 243, 556-562.

GLICK, N. B. (1970). Inhibitors of transport reactions. In Metabolic Inhibitors: a Complete Treatise, vol. 3, pp. 8-17. Edited by R. M. Hochster, M. Kates \& J. A. Quastel. London \& New York: Academic Press.

Gillin, F. D. \& DiAmond, L. S. (1981). Entamoeba histolytica and Giardia lamblia: effects of cysteine and $\mathrm{O}_{2}$ tensions on trophozoite attachment to glass and survival in culture media. Experimental Parasito$\log y$ 52, 9-17.

JARROLL, E. L. (1988). Effect of disinfectants on Giardia cysts. CRC Critical Reviews in Environmental Control 18 (in the Press).

Jarroll, E. L., Müller, P. J., Meyer, E. A. \& MORSE, S. A. (1981). Lipid and carbohydrate metabolism of Giardia lamblia. Molecular and Biochemical Parasitology 2, 187-196.

KULDA, J. \& NoHYNKovA, E. (1978). Flagellates of the human intestine and of intestines of other species. In Parasitic Protozoa, vol. 3, pp. 69-104. Edited by J. D. Kreier. London \& New York: Academic Press.

LINDMARK, D. G. (1980). Energy metabolism of the anaerobic protozoon Giardia lamblia. Molecular and Biochemical Parasitology 1, 1-12.

Lindmark, D. G. \& Miller, J. J. (1987). Enzyme activities of Giardia lamblia and Giardia muris trophozoites and cysts. In Advances in Giardia Research. Edited by P. Wallis and B. Hammond. Calgary, Canada: University of Calgary Press.

LLOYD, D. (1985). Simultaneous dissolved oxygen and redox measurements: use of polarographic, bioluminescence and mass spectrometric monitoring combined with dual wavelength spectrophotometry. In Gas Enzymology, pp. 37-53. Edited by H. Degn, R. P. Cox \& H. Toftlund. Dordrecht: Reidel.

Lloyd, D. \& Pedersen, J. Z. (1985). Metronidazole radical anion generation in vivo in Trichomonas vaginalis: oxygen quenching is enhanced in a drugresistant strain. Journal of General Microbiology 131, 87-92.

Lloyd, D., Mellor, H. \& Williams, J. L. (1983). Oxygen affinity of the respiratory chain of Acanthamoeba castellanii. Biochemical Journal 214, 47-51.

LloYd, D., Williams, J. L., YaRlett, N. \& Williams, A. G. (1982). Oxygen affinities of the hydrogenosome-containing protozoa Tritrichomonas foetus, Dasytricha ruminantium, and two aerobic protozoa, determined by bacterial bioluminescence. Journal of General Microbiology 128, 1019-1022.
MeYer, E. A. \& JARroll, E. L. (1980). Giardiasis. Journal of Epidemiology 111, 1-12.

Moreno, S. N. J., Mason, R. P., Muniz, R. P. A., CRUZ, F. S. \& DOCAMPO, R. (1983). Generation of free radicals from metronidazole and other nitroimidazoles by Tritrichomonas foetus. Journal of Biological Chemistry 285, 4051-4054.

Paget, T. A., Fry, M. \& LlOYd, D. (1987a). Effects of inhibitors on the oxygen kinetics of Nippostrongylus brasiliensis. Molecular and Biochemical Parasitology 22, 125-133.

Paget, T. A., Fry, M. \& Lloyd, D. (1987b). Hydrogen peroxide production in uncoupled mitochondria of the parasitic nematode worm Nippostrongylus brasiliensis. Journal of Biochemistry 243, 589-595.

Paget, T. A., Fry, M. \& Lloyd, D. (1988). The $\mathrm{O}_{2}$ dependence of respiration and $\mathrm{H}_{2} \mathrm{O}_{2}$ production in the parasitic nematode Ascaridia galli. Biochemical Journal 256, 880-889.

RICE, E. \& SchaEFFER, F. W., III. (1981). Improved in vitro excystation procedure for Giardia lamblia cysts. Journal of Clinical Microbiology 14, 709-710.

Roberts-Thompson, I. C., Stevens, D. P., Mahmoud, A. A. F. \& WARREN, K. S. (1976). Giardiasis in the mouse : an animal model. Gastroenterology 71, 57-61.

SAUCH, J. F. (1984). Purification of Giardia muris cysts by velocity sedimentation. Applied and Environmental Microbiology 48, 454-455.

Shaw, P. K., Brodsky, R. E., Lyman, D. O., Wood, B. T., Hibler, E. P., Healy, G. R., Macleod, K. I. E., Stahy, W. \& Schultz, M. G. (1977). A community-wide outbreak of giardiasis with evidence of transmission by municipal water supply. Annals of Internal Medicine 87, 426-432.

WEINBACH, E. C. (1980). Biochemistry of enteric parasitic protozoa. Trends in Biochemical Science 6, 254-257.

Wilhelm, E., Battino, R. \& Wilcock, R. J. (1977). Low pressure solubility of gases in liquid water. Chemical Review 77, 219-222.

Woods, L. F. J., Wood, J. M. \& GibBs, P. A. (1981). The involvement of nitric oxide in the inhibition of the phosphoroclastic system in Clostridium sporogenes by sodium nitrite. Journal of General Microbiology 125, 399-406.

WRIGHT, R. A. \& Vernon, T. M. (1976). Epidemic giardiasis at a resort lodge. Rocky Mountain Medical Journal 73, 208-211.

Veazie, L., Brownlee, I. \& Sears, H. J. (1978). An outbreak of gastroenteritis associated with Giardia lamblia. In EPA Symposium on Waterborne Transmission of Giardiasis, Cincinnati, Ohio, USA. Edited by W. Y. Jakubowski \& J. C. Hoff. EPA Publication 600/9-79-001. Washington, DC: US Environmental Protection Agency.

Yarlett, N., Rowlands, C. C., Yarlett, N. C., Evans, J. C. \& Lloyd, D. (1987). Reduction of niridazole by metronidazole-resistant and susceptible strains of Trichomonas vaginalis. Parasitology 94, 93-99 